\title{
Systematic aquaculture: yesterday, today, and tomorrow
}

\author{
HACHIRO HIRATA \\ Faculty of Agriculture, Kinki University, Nara 631-8505, Japan (hirata@m3.people.or.jp)
}

SUMMARY: The harmonization between aquaculture developments and the conservation of aquatic environments is the key to sustaining aquaculture. One of the obstacles to this harmonization is the negative economic relationship between developments and conservation. In order to sustain a systematic aquaculture, we need to establish benefits for both the human economy and the biological economy. The polyculture of Ulva and fish has been conducted by our group since 1964, with differing intents. Sakai was able to develop an abalone culture that fed on the U/va cultured in the fish farm, and these mollusks produced green pearls as a byproduct of this fish culture. In that way, human profit was harmonized with the biological economy. The whole aqua-crop ensilage (WACE) system has been lectured by Hirata since 1999. The fish culture introduces nutrients into the sea. The nutrients contribute to the growth of sessile organisms. Whole organisms are harvested and ensilaged to produce the probiotic feed. This feed is mixed with routine fish feed. Ruminated culture will also be applied for byproducing the rotifer in culture of fish. These systems will be developed in the future.

\section{KEY WORDS: systematic, ensilage, integrate, rotifer, polyculture}

\section{INTRODUCTION}

The hamonization between aquaculture developments and the conservation of aquatic environments is a key to sustaining aquaculture. However, one of the obstacles to this harmonization is the negative economic relationship between development and conservation. If we concentrated only on the human economy (socioecononiy), the biological economy would be in the red, with no benefits accrued In contrast, if we concentrated only on the biological economy, the human economy would be in the red, with no benefits accrued. For systematic aquaculture, we should establish benefits for both the human economy and the biological economy.

The biological economy named by Hohgetsu " in 1984 was based on the homeostasis of the ecosystem in the environment. The key to homeostasis is biological harmonization among the fauna, flora, and micro-flora in the environment ${ }^{2}$. This concept is easy to understand, but difficult to realize in practice. The challenge is how to gain benefits for all of these aspects of the biological economy, the fauns, flora, and micro-flora, at one time in one area.

Systematic aquaculture has been studied by many aquaculturists ${ }^{3-9,12-2)}$. In this paper, polyculture, or integrated aquaculture, and probiotic aquaculture are described as the systematic aquaculture of yesterday ${ }^{5-9)}$ and today ${ }^{12-21)}$. The whole aqua-crop ensilage system and ruminated aquaculture system are presented as the systematic aquaculture of tomorrow. Biological conversions from negative factors to positive factors are focused on in order to obtain profits for both the human economy and biological economy in the future. Fish feces, as the origin of water pollution, have been negative factors for the environment, but they can also be the origin of food resources, if we use them systematically as positive factors.
Recently, water recirculating culture systems ${ }^{3)}$ and hydroponics ${ }^{4}$ have been rapidly developing all over the world Kikuchi and Iwata ${ }^{3)}$ will review the water recirculating culture system in this session Schram et a $t^{4)}$ have presented the technical and financial benefits on the hydroponics of combined eel culture and tomato planting. These culture systems can be broadly included in the systematic aquaculture. However, the aims of systematic aquaculture are principally material recirculations (not only water recirculations) from aquaculture to aquaculture (not aquaculture to horticulture). The author like to present on the material recirculation based on the nature.

\section{SYSTEMATIC AQUACULTURE; YESTERDAY}

The homeostasis of ecosystems ${ }^{2}$ is a key factor enabling the coexistence of all the living beings on the earth to live. It is based on the harmony of fauna, flora, and microflora in the environment. This homeostasis has been developed and established by the organisms themselves. It is important to remember that they spent about a billion years establishing this system.

Most acquaculturnists, however, did not worry about the homeostasis of the ecosystem until the 1980's or 1990's. The fauna aquaculturists have been concentrating on fauna only, and the flora culturists on flora only. No one has concentrated on both the fauma and flora culture at one time in one area. There was no harmonization between the human economy and biological economy before the 1980's.

However, some trials on ecosystematic seedling productions of puffer and prawn were conducted by our group $^{59)}$ during 1964 and 1976 at the Seto Inland Sea Farming Association (SISFA). 


\section{1-1. Polyculture of puffer and $U l v a$ in the hatchery}

In order to maintain the homeostatis of the ecosystem in hatchery tanks, the polyculture of the puffer Takifugu rubripes as fauna and the Chorophyta Ulva pertusa as flora, were conducted by Hirata") in 1964 at Yashima St., SISFA. The water was recirculated from the fish rearing tank to the $U$. pertusa culture tank I estimated that the $U$. pertusa contributed these three advantages to cultivation of the puffer: 1) excess mutrient uptake, 2) carbon-dioxide consumption, and 3) oxygen supply. These experiments were unfortunately limited to preliminary trials, because of opposition expressed against them.

\section{1-2. Transportation of puffer polycultured with $U$ lva}

Hirata $^{6}$ also tried to polyculture the larvae of $T$. rubripes and $U$. pertusa in larval transportation tanks ( $100 \mathrm{~L}$ each). The covers of the tanks were specially made of transparent acrylic plastics. U. pertusa supplied oxygen into the water during the day by sunlight. Aeration was not supplied to the tank throughout transportation. However, the supply of oxygen was restricted to the daytime only, due to no light at night Approximately 10,000 larvae were transported from Yashima Station, Kagawa Prefecture to Ooshima Island, Nihama, Ehime Prefecture by truck. It took about 4 hours. No fish died while being transported.

\section{1-3. Systematic $2,500 \mathrm{~m}^{3}$ prawn hatchery}

A semi-natural ecosystematic prawn hatchery was designed by Hirata ${ }^{7}$ and constructed at the Shibushi Station, SISFA in 1969. The size of the hatchery was about $2,500 \mathrm{~m}^{3}(32 \mathrm{x}$ $20 \times 4 \mathrm{~m}$ ). The ecological material cycle in the rearing water was promoted by a movable aerator system and zigzag stream unit $\left(450 \mathrm{~m}\right.$ with $\left.50 \mathrm{~m}^{3}\right)$, which was connected to the hatchery. The bottom of the hatchery was cleaned by the movable aerator, which was moved slowly (at the rate of about $1 \mathrm{~m} / \mathrm{min}$ ) by the reduction motors. The waters were recirculated from the hatchery to the stream units, when needed.

The zoeal larvae were fed mashed soybean cakes as the probiotic diets ${ }^{8}$. The feces were converted to the nutrients for algae. These biological conversion systems were promoted by the movable aerator. The results obtained in 1975 and 1976 on the seedling production of the prawn Penaeus joponicus are illustrated in Table 1, after Mori et a $P^{\text {) }}$. The average number of post larvae produced was $27.33 \mathrm{x}$ $10^{6}$ individuals per lot. The average survival rate was $84.8 \%$, and the CV\% was $11.4 \%$ of the whole. The production technique of this system was higher and more stable than those conducted using routine methods. The hatchery scale was huge; $2,500 \mathrm{~m}^{3}$. It closely resembled the natural condition found in the wild.

This huge hatchery system was based on the ecosystem found in nature. However, the construction costs of the system were quite expensive (about 60 million yen in 1968 and 1969). The numing costs were also expensive. It was difficult to estimate the budgets between the biological economy and the human economy. Perhaps, the biological economy in this hatchery ran in the black, but the human economy ran in the red.

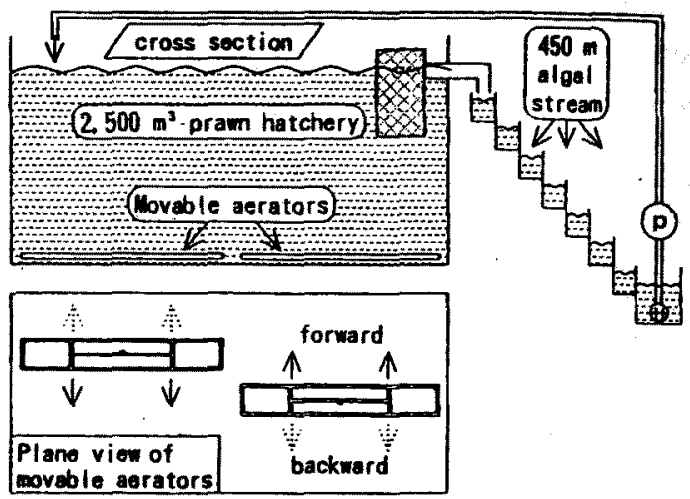

Fig. 1. Cross section (up) of the systematic $2,500 \mathrm{~m}^{3}$ prawn hatchery and plane view (down) of movable aerators on the bottom of the tank. The stream units $(450 \mathrm{~m})$ were additionally constructed for promoting the material cycle in the hatchery.

Table 1. Results of seadling production of the prawn $P$. japonicus in 1975 and 1976 in the $2500 \mathrm{~m}^{3}$ hatchery at Shitushi Station, SISFA. The stream units were not used in these lots. (Afler Mori et $a^{(?)}$ ).

\begin{tabular}{lcccc}
\hline \hline Period & & $\begin{array}{c}\text { No. of zoea-I } \\
\left(\times 10^{6} \text { ind }\right)\end{array}$ & $\begin{array}{c}\text { No. of post larvae } \\
\left(\times 10^{6} \text { ind }\right)\end{array}$ & $\begin{array}{c}\text { Survival rates } \\
(\%)\end{array}$ \\
\hline Apr -Jun & 1975 & 19 & 16 & 84.2 \\
Jur-Aug & 1975 & 33 & 32 & 97.0 \\
Aug-Sep & 1975 & 28 & 20 & 71.4 \\
Apr -Jul & 1976 & 39 & 30 & 76.9 \\
Jur-Aug & 1976 & 40 & 39 & 97.5 \\
Aug-Sep & 1976 & 33 & 27 & 81.8 \\
\hline Average & & 32.00 & 27.33 & 84.80 \\
SD & 7.07 & 7.61 & 9.67 \\
CV\% & 22.09 & 27.82 & 11.40 \\
\hline
\end{tabular}

\section{SYSTEMATIC AQUACULTURE; TODAY}

In the 1980 s, the water environment in fish farms were polluted by excess nutrients, which were caused by the rapid development of mariculture. Red tide organisms bloomed frequently because of the nutrients produced in the farms each year. Culturists have gradually understood how important the ecosystems in the farms are.

\section{2-1. Food-chained polyculture of fish and $U l v a$}


The polyculturing of fauma and flora are ecosystematic attempts for mitigating the self-pollution in mariculture farms. However, most algae bloom in winter and spring when most cultured fish are resting. In 1985, Migita ${ }^{83}$ reported on finding sterile $U$. pertusa that bloomed in the summer, which he observed in Ohmura Bay, Nagasaki Prefecture. The sterile $U$. pertusa was found to be a suitable strain for mitigating pollution in mariculture envirorments in summer. Therefore, we started to culture U. pertusa again.

Food-chained polyculture-1: Xu et $a l^{11-12)}$ studied the polyculture of the flounder Paralichthys olivaceus and sterile U. pertusa in the aquaria $(60 \mathrm{~L})$. They found that the ammonia uptake by U. pertusa were $74,76,89,87$, and 79 mole/g-weth) under different temperatures of $18,21,24,27$, and $30{ }^{\circ} \mathrm{C}$, respectively. They also tried to feed $U$. pertusa to the $P$. olvacens. The optimum additive ratio was estimated to be $2 \%$ of the foods supplied. The growth rates of fish fed diets supplemented with $U$. pertusa were faster than that of the control group.

Recently, Kawabe and his associates ${ }^{22}$ established a commercially-based polyculture system of the $P$. olivaces and U. pertusa in the mountainous area called "Okuhida," in Gifu Prefecture. The total capacities of the aquaria employed for $P$. olnuces, $U$. pernusa, and sand filters were $102 \mathrm{~m}^{3}, 16 \mathrm{~m}^{3}$, and $9 \mathrm{~m}^{3}$, respectively. All of the sea waters were artificially made and recirculated in those tanks. The advantage of this system was its use of "electronically-charged water." The fish thrived in this environment. According to Kawabe's data the $U$. pertusa grew well in the waters of this system. The survival rates of the juveniles within 3 months were 90 to $97 \%$. Best cropping rate of $U$. pertusa in this system was about 10 wet-kg/week ( $\left.{ }^{2}\right)$ Private communication)

Food-chained polyculture-2: In 1992, Yamauchi et al ${ }^{13-14)}$ examined the polyculture of the red sea bream Pagnis major and $U$. pertusa in a cage culture farm at the Azumacho Fish Raising Center, in Kagoshima Prefecture. The $U$. pertusa were cultured at the surface of the cage. The P. major were reared in the middle and bottom parts of the cage, as shown in Fig 2. The control cage was covered by shadow nets as usual, in order to protect the fish from sunbum.

The $U$. pertusa harvested in the polycultured cage weighed $42.5 \mathrm{~kg}$ on September $21 \mathrm{st}$ and February 7 th All of them were fed back to the polycultured red sea bream. The food conversion rates in the experimental group and control group were $50.5 \%$ and $48.4 \%$, respectively (Table 2 ). The color of the fish in the experimental group was redder than that of the control group. In terms of body sliminess, the "numer" were thicker in the experimental group. The fish in the polycultured group were more active and healthier than that of the control group.

In 1993, Hirata et al ${ }^{15)}$ examined the budgets of both oxygen and carbon-dioxide in the cage mentioned above.
Oxygen in $\mathrm{pO}_{2}$ and carbon-dioxide in $\mathrm{pCO}_{2}$ were determined by Radiometer ABL 330.

The $\mathrm{pCO}_{2}$ in the experimental cage was $4 \%$ lower than that in the control cage. However, the $\mathrm{pO}_{2}$ was augmented $9 \%$ compared to the control The decrease of $\mathrm{pCO}_{2}$ and the increase of $\mathrm{pO}_{2}$ in the experimental cage may be attributed to the $\mathrm{CO}_{2}$ metabolisms by $U$. pertusa polycultured in the cage.

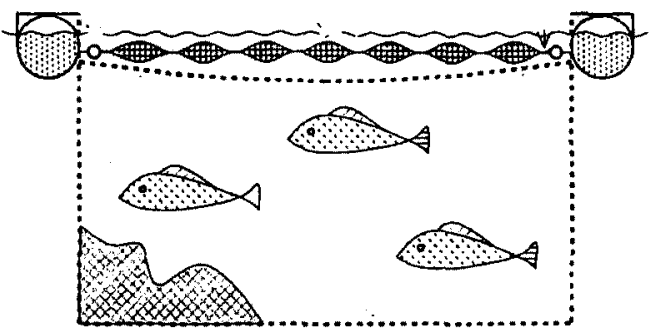

Fig 2. Schematic view of the polyculture of $P$. major and $U$. pertusa in the cage. $U$. pernusa were cultured on the surface in bag-nets. (After Hirata et al $^{\text {l5) }}$

Table 2. Effects of probiatic additive feading on food conversion rates of red sea bream. (After Yamauchi et al ${ }^{13}$ )

\begin{tabular}{lccccc}
\hline \hline & $\begin{array}{l}\text { Pellets } \\
\text { supplied } \\
\text { (dry-kg) }\end{array}$ & $\begin{array}{l}\text { Uva } \\
\text { cropped } \\
\text { (dry-kg) }\end{array}$ & $\begin{array}{l}\text { Total } \\
\text { foods } \\
\text { (dry-kg) }\end{array}$ & $\begin{array}{c}\text { Fish weight } \\
\text { gained } \\
\text { (wet-kg) }\end{array}$ & $\begin{array}{c}\text { Fond } \\
\text { conversion } \\
\text { (\%) }\end{array}$ \\
\hline Probiotic & $2,606.0$ & 42.5 & $2,648.5$ & $1,315.8$ & 51.34 \\
Control & $2,634.0$ & - & $2,634.0$ & $1,275.1$ & 48.4 \\
\hline
\end{tabular}

\section{2-2. Integrated aquaculture systems}

Integrated aquaculture systems were initiated in China more than 100 years ago. Integrated aquaculturing between carp culturing and silk worm culturing was typical. Now, integrated aquaculture systems have become trendy in aquaculture throughout the world Most systems of integrated aquaculture were developed by farmers themselves.

Integrated mariculture: Sakai ${ }^{3}$, an abalone pearl culturist, was interested in using the summer type of sterile $U$. pertusa as food for culturing abalone. He tried many different experiments on abalone pearl culturing and was finally able to figure out how to obtain emerald green pearls from the abalone, by feeding them $U$. pertusa. The rarity and value of green pearls is much higher than that of routine pearls. Therefore, the price of green pearls is quite expensive $U$. pertusa serves as a good stabilizer for the abalone. Therefore, the $U$. pertusa are fundamental to the process.

Recently, the integrated mariculture of yellowtail, $U$. pernusa, and abalone have been extended by many fishermen and/or fisherwomen in Nagashimacho, Kagoshima Prefecture. The excess nutrients supplied by the yellowtail have been consumed by the $U$. pertusa. This indicates how the development of mariculture and the 
conservation of the environment have been harmonized through the use of $U$. pertusa. $\left({ }^{3)}\right.$ Oral presentation in the $I^{\text {s }}$ Symposium on Fisheries Development, 1995 at Azumacho)

Integrated land-based mariculture: The most advanced integrated mariculture systems have been developed by Shpiegel $e t a l^{16)}$ and Neori $e t a l^{17-18)}$ in Israel They tried integrated, land-based mariculture of sea bream, U. lactuca, and abalone. According to their report, $1 \mathrm{t}$ of sea bream produces nearly $0.5 \mathrm{~kg}$ ammonia-N/d. The mutrients produced by the sea bream were removed by the $U$. lactuca biofilters cultured in the $120 \mathrm{~m}^{2}$ tanks. In their business plan, the S.O.M. Enterprises states that they expect to produce up to $15 \mathrm{MT}$ each of sea bream and abalone in $3-4$ years.

\section{2-3. Probiotic aquaculture systems}

The polyculture or integrated mariculture systems mentioned above concentrate on the culture of fauna and flora However, in order to maintain the homeostasis of ecosystems in an aquaculture environment, the harmonization among fauna, flora, and micro-flora is necessary. Therefore, probiotic aquaculture, including micro-flora, support the homeostasis of the ecosystem.

Promoting "algal growth potentials": In 1997, probiotic aquaculture system has been the subject of loctures by myself at Amakusa Islands, Kumamoto Prefecture. Then, the project team ${ }^{19)}$ on the probiotic mariculture system was initiated in the Islands supported by the Kumamoto Prefectural Government. The team were organized by the Kumamoto Mariculture Cooperative. The culture experiments were made in the Tsunumaru Mariculture Farms at Fukami Bay in the Islands. The probiotics "Amakusa PX" were made by the Farms and fed to the yellowtail Seriola quinqueradiata cultured in the cages.

Interesting results were observed in algal growth potential (AGP). The AGP were demonstrated in culture of Nannochoropsis oculata by the fish feces collected near the culture cages by the sediment traps. The results are presented in Fig. 3. AGP in the fish fed probiotics with $5 \%$ of total foods supplied Showed higher AGP than that of control cages

The results were quite important to realize the promotion of the material cycle in the waters. Nirro and Hirata ${ }^{201}$ in 2000 and Hirata et a ${ }^{21)}$ in 2001 obtained almost same results in culture of carp Cyprinus carpio.

Niro and Hirata ${ }^{2)}$ examined the effects of probiotic additives, EG (Earth Genitor), AP (Amakusa PX), and CY (Commencial Yogurts) on ecology, especially algal growth potentials (AGP) in the culturing of carp C. carpio. The results are summarized in Table 3.

Although there were no significant differences in each group, the fecal volume was higher in the control group, and lower in the EG group. AGP was higher in EG, and lower in the control TP was higher in the control, but lower in the EG. It can be concluded that the probiotic additives were more effective on material cycles in waters than that of the routine methods

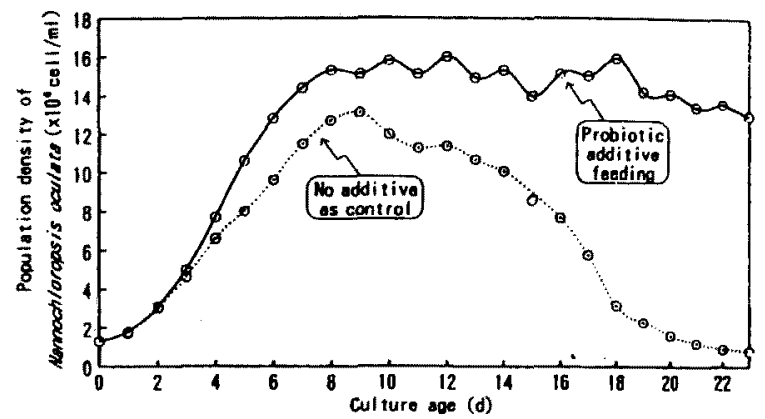

Fig. 3. Effects of probiotic additive feeding on algal gowth potential in culture of S. quinqueradiata. (After Hirata et al ${ }^{19}$ )

Table 3. Fecal volume FV, algal growth potential AGP, total nitrogen TN, and total phosplate TP in culture water of carp fed different probiotic additives. (After Niiro and Hirata ${ }^{22)}$ )

\begin{tabular}{lcccc}
\hline \hline Group & $\begin{array}{c}\text { Fecal V. } \\
\text { (ml) }\end{array}$ & $\begin{array}{c}\text { Algal GP } \\
\left(\times 10^{7} \text { cell/ml) }\right.\end{array}$ & $\begin{array}{c}\text { T. Nitrogen } \\
\text { (mg/g) }\end{array}$ & $\begin{array}{c}\text { T. Phosphate } \\
\text { (mg/g) }\end{array}$ \\
\hline EG & 59.3 & 1.7 & 45.5 & 43.4 \\
AP & 64.3 & 1.6 & 49.6 & 51.0 \\
CY & 60.0 & 1.5 & 52.1 & 43.6 \\
Control & 66.1 & 1.4 & 52.3 & 54.9 \\
\hline
\end{tabular}

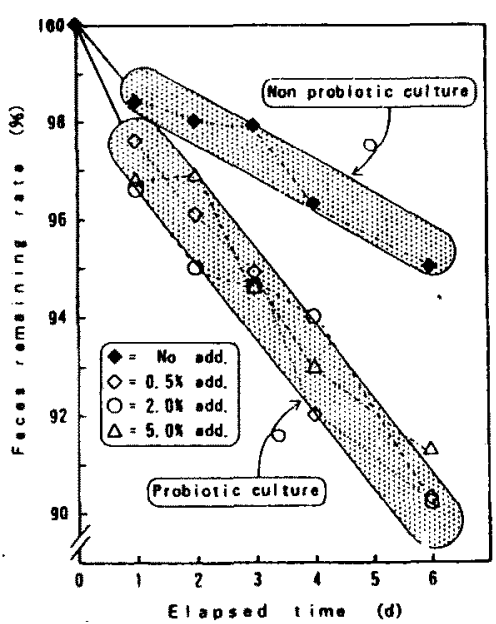

Fig. 4. Progress of fecal remaining rates in the different rates of additive rates. (After Niiro and Hirata ${ }^{23)}$

Reducing "fecal remaining rates": Niro and Hirata ${ }^{23)}$ examined the effects of probiotic additives, Earth Genitor, on the fecal remaining rates (FRR) in cultured $C$. carpio. The experiments were performed on four groups, A, B, C, and D, at the different additive rates of $0,0.5,2$, and $5 \%$, respectively

The FRR in group A ( $0 \%$ as control) was $0.83 \% / d$, while the FRR in the probiotic additive groups B, C and D were $1.62,1.63$, and 1.43\%/d respectively (Fig 4). The FRR in the probiotic additive groups were about two times 
higher than that of the control group.

The results indicate that probiotic additive foods promote material cycles in the water. In other words, it may be suggested that the cultured carp fed probiotic additives seem to carry the mobile bio-filter.

\section{SYSTEMATIC AQUACULTURE; TOMORROW}

In order to achieve harmony between aquacultural development and environmental conservation, bioconversion technology from negative to positive features should be artificially introduced. For example, the feces of cultured fish were previously considered negative features. However, today, they are inreplaceable fertilizers for algae. The idea of bioconversion is based on natural concepts.

Two proposals for the systematic aquaculture of tomorrow are presented below. One is marine-based, and the other is land-based. Both are grounded on the idea of providing assistance to the natural roles. The benefits for both the human economy and biological economy will hopefully result in a budget in the black.

\section{3-1. Whole aqua-crop ensilage system in mariculture}

The principle of "whole aqua-crop ensilage" (the WACE) system is to promote the material cycle in mariculture farms by using the potential power of fauma, flora, and micro-flora The WACE research group was initiated in Kagoshima Pref., Japan, following the $3^{\text {rd }}$ Symposium on Fisheries Development. In the summer of 2001, Yamasaki, Yamauchi, and

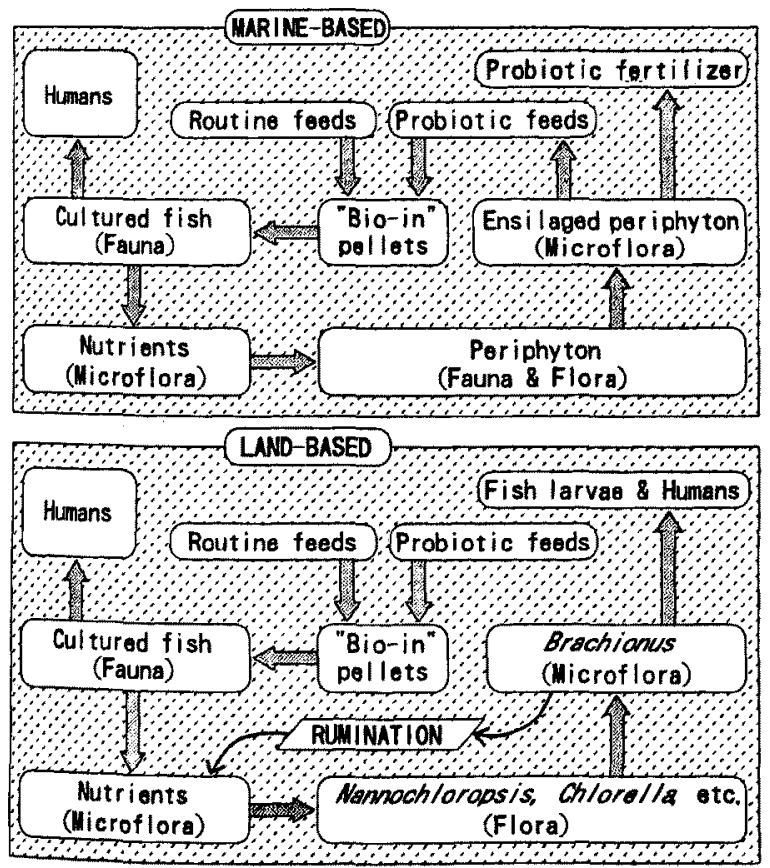

Fig. 5. Flow-chant of the systematic aquaculture for tomorrow. Upper: Whole aqua-crop ensilage (WACE) system in marine-based ${ }^{44}$. Lower: Ruminated aquaculture system in land-based. Hopefully there are good harmonization between the human and biological economies. their associates tried to crop periphyton in the farms of the Azumacho Marine Fish Raising Center. About $200 \mathrm{~kg}$ of the periphyton, consisting of Ulva, Mytilus, Styela, Pinctada, Pseudocentrotus, etc., were crushed and ensilaged for 45 days by YM probiotics in high temperatures (more than $120^{\circ} \mathrm{C}$ ) at the Takarabe Factory of Sanyu Co. Ltd.

Some chemical contents in the WACE probiotics are presented in Table 4. The advantages of the WACE system are considered as follows: 1) The culture of periphyton offer fish apartments like "payao" in the farms ${ }^{24)}$. 2) The periphyton consume excess mutrients in the farms. 3) The periphyton contribute as probiotic food resources after ensilage. The WACE system will be hopefully implemented

Table 4. Some chenical compositions of the WACE probiotics produced by the WACE research group in 2001. The probiotic materials were analyzed by Japan Food Research Laboratories ordered by the Sanyu Co. Ltd and the author.

\begin{tabular}{lc}
\hline Items analyzed & Contents (\%) \\
\hline Total nitrogen & 1.86 \\
Total phosphate & 2.24 \\
Total potassium & 0.24 \\
Moisture & 22.5 \\
Crude protein & 12.2 \\
Crude fat & 1.2 \\
Crude fiber & 2.4 \\
Crude ash & 48.9 \\
Soluble inorganic nitrogen & 12.8 \\
POV & (undetected) \\
\hline ") not enough fat for analyzing
\end{tabular}

\section{3-2. Ruminated aquaculture systems on the lands}

Ruminated aquaculture systems are simple, because the systems are based on systems in nature. The fish culture introduces nutrients into the waters, contribute to the growth of phytoplankton. The phytoplankton are an essential food for zooplankton, which in tum are produced as "byproducts" of the cultured fish. The feces of the zooplankton are also reused, as nutrients for the phytoplankton again.

Preliminary experiments on this systematic aquaculture for tomorrow were preliminarily made using $60 \mathrm{~L}$ glass aquaria with the Electron-charger in the summer of 2001. C carpio, were cultured in tank-A. The salinity of the rearing water was adjusted to about $10 \mathrm{psu}$. The fish were fed "Bio-in" feed supplemented with the EG probiotics. Phytoplankton $N$. oculata were inoculated in tank-A. When $N$. oculata bloomed in tank-A, the algae were transferred into tank-B. Rotifer Brachiomus plicatilis were then inoculated into tank-B. When B. plicatilis bloomed, they were harvested. The procedures were repeated for 30 days. The daily growth rates of $C$. carpio and $B$. plicatilis 
were $1.2 \mathrm{~g} / \mathrm{d}$ and $3.1 \mathrm{~g} / \mathrm{d}$ respectively. The byproducts were 2.6 times higher than that of the main products. Of course, the water was cleaned by the growth of $N$. oculata.

$B$. plicatilis are irreplaceable food for fish larvae, and must be nutritious food for humans, too. The biological economy will hopefully provide more benefits than the human economy in the culturing of fish in the near future.

\section{CONCLUSIONS}

The most important task we face is changing our conceptions about the excretions by the cultured fish. Fish feces have been considered sources of water pollution both yesterday and even today. The author would like to suggest that fish feces are sources of food for fish or for humans. The best medium for the sessile organisms is the feces of fish Byproducts of rotifer recycled by the feces was estimated to be greater than that of fish productions. Mutuality among the fauna, flora, and micro-flora is the principle of nature. We should apply them systematically to the aquaculture. Then, the human economy and biological economy in aquaculture will be harmonized.

\section{ACKNOWLEDGEMENTS}

The author would like to thank Dr. H. Kurokura, Professor of University of Tokyo, for nominating him to present the keynote lecture in this session. The author also would like to express his heartfelt thanks to Mr. S. Yamamura, President of Sanyu Co. Ltd., Dr. S. Kadowaki, and Dr. S. Yamasaki, Professors of Kagoshima University, and Mr. T. Yamauchi, Acting Director of Azumacho Marine Fish Raising Center for preparing the WACE pellets and this manuscript.

\section{REFERENCES}

1. Hohgetsu $K$. Ecosysgtem and socio-economy, in "Biological economy." Shoukado, Tokyo, 1984, pp.228-234. In Japanese

2. Odum EG. Fundamentals of Ecology. Saunders, Philadelphia, 1971, (Trans. Ed, Baifukan, Tokyo, 1974, pp. 10-136).

3. Kikuchi $\mathrm{K}$, Iwata $\mathrm{N}$. Closed recirculaling aquaculture of Japanese flounder. European Aquacult. Soc., Special Pub. 2001; 29. 138-139.

4. Schram E, Kloct CJ, Kempkes FLK. Technical and financial benefits from integrating intensive fish farming and horticulture. Eunopian Aquacult. Soc., Special Pub. 2001; 29: 235-236.

5. Hirata H Seedling production of puffer. Yashola. 1964; 1(11): 31-37. In Japanese

6. Hirata $H$ Some trials on the seed production of puffer. Saibai-Gyogyo 1964; 1: 1-5. In Japanese

7. Hirata $\mathrm{H}$. An introduction to the rearing methods of prawn, Penaeus japonicus BATE in Japan. Mem. Fac. Fish, Kagoshima Univ. 1975; 24: 7-12.

8. Hirata $\mathrm{H}$, Mori $\mathrm{Y}$, Watanabe M. Rearing of prawn larvae, Penaeus japonicus, fed soy-cake particles and diatoms. Mar. Biol. 1975; 29 :
9-13.

9. Mori $Y$, Kuncha N, Nakanishi T, Wada T, Wadanabe M, Hirata H. Seodling production of Kunuma prawn in $2,500 \mathrm{~m}^{3}$ hatchery. Occasional Notes, Shibushi St, SISFA. 1976; 1-2 (mimeographs)

10. Migita S. Variation of striled Uha pertusa in Ohmura Bay. Res. Rep. Fac. Fish. Nagasaki Univ. 1985; 59: 33-37. In Japamese Abstr

11. Xu BT, Hirata H. Effects of feed additive Uhva reproduced in a feedback culture system on the survival and growth rates of Japanese flounder, Paralichthys olivaceus juveniles and purification of the rearing water. Stasanzonshola 1991; 40 . 207-213. In Japanese with Abstr.

12. Xu BT, Yamasaki S, Hirata H. Supplementary Ulva sp. var. meal level in diet of Japanese flounder, Paralichthys olnoceus. Suisannzoushoku 1993; 41: 461-468. In Japanese with Abstr.

13. Yamauchi T, Matsuda M, Yamasaki S, Hirata $H$ Polyculture of rod sea bream and Ulua pertusa in the cage. Yosholu 1994, 38(5): 68-71. In Japanese

14. Yamauchi T. Polyculture of red sea bream Pagnis major and Uha in the cage. In Hirata $\mathrm{H}$, Notoya M. (eds) Polyculturing of flora and fama. Seizando-Shoten, Tokyo. (in press).

15. Hirata $H$, Yamasaki S, Maenosono $H$, Nakazono T, Yamauchi T, Matsuda $\mathrm{M}$ Relative budgets of $\mathrm{pO}_{2}$ and $\mathrm{pCO}_{2}$ in cage polycultured red sea bream, Pagnus major and sterile Uha sp. Suisanzoushoła 1994; 42: 377-381.

16. Shpigel $M$, Neori $A$. The integrated culture of seawead, abalone, fish and clams in modular intensive land-based system. I Proportions of size and projected revenues. Aquacultural Engineering, 1996, 15: 313-326.

17. Neori A, Shpigel M, Ben-Eua D. Sustainable integrated system for culture of fish, seaweed and abalone. Aquaculture 2000; 186: 279-291.

18. Neori A, Shpigel M, Scharfstein B. Land-based lowpolhtion integrated mariculture of fish, seaweed and herbivores: Principles of development, design, operation and economics. Europion Aquacult. Soc., Special Pub. 2001, 29, 190-191.

19. Hirata $H$, Hirata I, Imamichi $H$, Tsurumaga $S$. Effect of probiotics Amakusa PX on algal growth potential inoculated by the feces of cultured yellowtail. Workshop Notes on Reasonable Mariculture Management in Kumamoto 1998; 2: 1-4. In Japanese

20. Niiro M, Hirata $H$. Effects of probiotic additive feoding on fecal remaining rates in culturing of carp Cyprimus carpio. Suisanzosholau, 2000, 48, 531-536. In Japanese

21. Hirata $H$, Tei $T$, Nirro $M$. Effects of probiotic additive feeding on water quality and algal growth potential in a culture of the carip Cyprimus carpio. Mem. Fac. Agricult., Kinki Univ. 2001; 34: 89-93. In Japanese with Abstr.

22. Niro $\mathrm{M}$, Hirata $\mathrm{H}$. Effects of probictic additive feodings on algal growth potentials and fecal decomposition rates in cultured carp, Cyprinus carpio. Suisanzoshoku 2001; 49: 91-96.

23. Nïro $\mathrm{M}$, Hirata $\mathrm{H}$. Effects of probictic additive feeding on algal growth potential in culturing of carp Cyprimus carpio. Suisanzoshoku 1999; 47: 583-587. In Japanese with Abstr.

24. Okamura $Y$, Tanaka $H$, Hirata $H$. Seasonal variations of the fish fauna in an algal float. Suisarzoshoła 1992; 40: 355-361. In Japanese with Abstr. 